\title{
Effects of thiamine on vasopressor requirements in patients with septic shock: a prospective randomized controlled trial
}

\author{
Suttasinee Petsakul ${ }^{1,2^{*}}$ (D), Sunthiti Morakul ${ }^{1,3}$, Viratch Tangsujaritvijit ${ }^{1,4}$, Parinya Kunawut ${ }^{1,5}$, \\ Pongsasit Singhatas ${ }^{1,6}$ and Pitsucha Sanguanwit ${ }^{1,7}$
}

\begin{abstract}
Background: Thiamine, an essential vitamin for aerobic metabolism and glutathione cycling, may decrease the effects of critical illnesses. The objective of this study was to determine whether intravenous thiamine administration can reduce vasopressor requirements in patients with septic shock.

Methods: This study was a prospective randomized double-blind placebo-controlled trial. We included adult patients with septic shock who required a vasopressor within 1-24 h after admission between March 2018 and January 2019 at a tertiary hospital in Thailand. Patients were divided into two groups: those who received $200 \mathrm{mg}$ thiamine or those receiving a placebo every $12 \mathrm{~h}$ for 7 days or until hospital discharge. The primary outcome was the number of vasopressor-free days over 7 days. The pre-defined sample size was 31 patients per group, and the study was terminated early due to difficult recruitment.
\end{abstract}

Results: Sixty-two patients were screened and 50 patients were finally enrolled in the study, 25 in each group. There was no difference in the primary outcome of vasopressor-free days within the 7-day period between the thiamine and placebo groups (mean: 4.9 days (1.9) vs. 4.0 days (2.7), $p=0.197$, mean difference $-0.9,95 \% \mathrm{Cl}(-2.9$ to 0.5$)$ ). However, the reductions in lactate $(p=0.024)$ and in the vasopressor dependency index $(p=0.02)$ at $24 \mathrm{~h}$ were greater among subjects who received thiamine repletion vs. the placebo. No statistically significant difference was observed in SOFA scores within 7 days, vasopressor dependency index within 4 days and 7 days, or 28-day mortality.

Conclusions: Thiamine was not associated to a significant reduction in vasopressor-free days over 7-days in comparison to placebo in patients with septic shock. Administration of thiamine could be associated with a reduction in vasopressor dependency index and lactate level within $24 \mathrm{~h}$. The study is limited by early stopping and low sample size.

Trial registration: TCTR, TCTR20180310001. Registered 8 March 2018, http://www.clinicaltrials.in.th/index.php?tp= regtrials\&menu=trialsearch\&smenu=fulltext\&task=search\&task2=view1\&id=3330.

Keywords: Thiamine, Vasopressor requirement, Septic shock

\footnotetext{
* Correspondence: p.suttasinee@gmail.com

'Department of Critical Care Medicine, Faculty of Medicine, Ramathibodi Hospital, Mahidol University, Ratchathewi, Bangkok 10400, Thailand

${ }^{2}$ Department of Anesthesiology, Faculty of Medicine, Prince of Songkla University, Hatyai, Songkhla 90110, Thailand

Full list of author information is available at the end of the article
}

(C) The Author(s). 2020 Open Access This article is licensed under a Creative Commons Attribution 4.0 International License, which permits use, sharing, adaptation, distribution and reproduction in any medium or format, as long as you give appropriate credit to the original author(s) and the source, provide a link to the Creative Commons licence, and indicate if changes were made. The images or other third party material in this article are included in the article's Creative Commons licence, unless indicated otherwise in a credit line to the material. If material is not included in the article's Creative Commons licence and your intended use is not permitted by statutory regulation or exceeds the permitted use, you will need to obtain permission directly from the copyright holder. To view a copy of this licence, visit http://creativecommons.org/licenses/by/4.0/ The Creative Commons Public Domain Dedication waiver (http://creativecommons.org/publicdomain/zero/1.0/) applies to the data made available in this article, unless otherwise stated in a credit line to the data. 


\section{Background}

Thiamine is a water-soluble vitamin-containing antioxidant. In the aerobic metabolism of cells, thiamine is an essential vitamin, acting as a cofactor of pyruvate dehydrogenase and alpha-ketoglutarate transketolase of the Krebs cycle as well as in the pentose-phosphate shuttle that occurs in mitochondria [1]. An experimental sepsis model study found that thiamine deficiency was associated with greater oxidative stress and inflammatory responses [2]. In addition, thiamine deficiency in rats could produce more reactive oxygen species (ROS) as a consequence of acidosis, with an increase in cell apoptosis [3]. Thiamine is one of the metabolic resuscitators shown to produce nicotinamide adenine dinucleotide phosphate (NADPH) in glutathione cycling, inhibiting ROS and resulting in a decrease in microvascular dysfunction, cellular apoptosis and endothelial dysfunction [4].

Patients with septic shock have high metabolic consumption and have been observed to have many manifestations similar to patients with thiamine deficiency syndrome, including vasodilatation, hypotension, cardiac failure and elevated lactate levels [5]. A retrospective study reported the prevalence of thiamine deficiency in septic shock patients to be approximately 20-70\%, and patients who survived had a significantly higher body thiamine status than those who died [6]. One retrospective study showed that early use of intravenous thiamine in patients with septic shock was associated with improved lactate clearance and reduced 28-day mortality [7]. However, a recent observational study found, in a nationwide database investigation, no results that supported an association between an early thiamine administration dose after admission and 28-day mortality [8]. To date, clinical evidence outcomes of thiamine remain inconsistent, and thiamine doses of $400 \mathrm{mg}$ per day appear to be safe in clinical trials and may reduce lactate clearance $[9,10]$. We hypothesized that thiamine administration in patients with septic shock would decrease vasopressor requirements and organ failure compared with the corresponding outcomes in patients who did not receive thiamine; this was based on the hypothesized role of thiamine as a metabolic resuscitator.

\section{Methods}

We performed a prospective single-centre randomized double-blind placebo-controlled study to determine whether thiamine administration is associated with improvements in clinical outcomes for patients with septic shock. Patients were enrolled at Ramathibodi Hospital, Mahidol University - a tertiary academic medical centre. The study was approved by The Committee on Human Rights, Related to Research Involving Human Subjects and based on the Declaration of Helsinki, Faculty of Medicine Ramathibodi Hospital, Mahidol University (protocol number: ID 12-60-05). Patients or relatives provided written informed consent prior to enrolment. The trial was registered in the Thai Clinical Trials Registry (TCTR20180310001).

We enrolled consecutive patients between March 2018 and January 2019. We included adult patients ( $\geq 18$ years) who had suspected infections, showed a Sequential Organ Failure Assessment (SOFA) score $\geq 2$, were on a vasopressor or had been administered inotropic drugs for at least $1 \mathrm{~h}$ but no more than $24 \mathrm{~h}$, and had a lactate level $>2$ $\mathrm{mmol} / \mathrm{L}$; these patients were enrolled from emergency departments or the inpatient department unit. We excluded patients based on the following criteria: (1) receipt of thiamine $>100 \mathrm{mg}$ within $24 \mathrm{~h}$ before enrolment, (2) thiamine allergy or anaphylaxis, (3) pregnancy, (4) cancer or diseases having a 6-month survival rate $\leq 50 \%$ and (5) diagnosed cardiac beriberi, peripheral beriberi, WernickeKorsakoff syndrome or re-feeding syndrome.

Patients were randomized via 1:1 block computergenerated randomization with conceal envelope technique to receive either thiamine or a placebo. Patients in the thiamine group received $200 \mathrm{mg}$ of thiamine hydrochloride (vitamin $\mathrm{B}_{1}$ ) in $50 \mathrm{~mL}$ of $5 \%$ DW every $12 \mathrm{~h}$, with continued infusion for $30 \mathrm{~min}$. Patients in the placebo group received $50 \mathrm{~mL}$ of $5 \%$ DW every $12 \mathrm{~h}$, with continued infusion for $30 \mathrm{~min}$, for 7 days or until discharge of both groups. The placebo was identical in appearance to thiamine; patients, caregivers and outcome assessors remained blinded throughout the study period. Other septic shock management protocols, such as fluid resuscitation, antibiotics and septic work-ups, followed the Surviving Sepsis Campaign guidelines, 2016 [11].

The primary outcome of the present study was vasopressor-free days over 7 days, defined as the number of days in which patients did not receive vasopressor assistance within 7 days after randomization.

Secondary outcomes included lactate reduction and vasopressor dependency index reduction within $24 \mathrm{~h}$ after intravenous administration of thiamine, changes in the vasopressor dependency index from baseline to day 7 (or sooner if the patient was discharged), changes in SOFA scores from baseline to day 7 (or sooner if the patient was discharged) and 28-day mortality. Due to the effects of thiamine possibly being shorter than 7 days, patients would either recover or die. We conducted post hoc analyses of the effects of thiamine on changing SOFA scores, the vasopressor dependency index over 4 days and the difference between SOFA scores on days 1 and 4, as similarly performed in previous studies [7].

Thiamine levels were analysed in plasma via the fluorescence technique, which measured thiamine diphosphate (thiamine pyrophosphate), in which the most important and active form is an intracellular compound, making it the best marker of thiamine nutritional status. 
Thiamine deficiency, utilizing this technique, was defined as a level less than $70 \mathrm{nmol} / \mathrm{L}$ [12].

The vasopressor dependency index was calculated from the inotropic score divided by the mean arterial pressure $($ inotropic score $=($ dopamine dose $\times 1)+($ dobutamine dose $\times 1)+($ adrenaline dose $\times 100)+($ noradrenaline dose $\times 100)+($ phenylephrine dose $\times 100)$ ), and all doses were expressed as $\mathrm{mcg} / \mathrm{kg} / \mathrm{min}$ [13].

After patients were enrolled, all patient demographic data were recorded, and blood was drawn for collection to measure the arterial lactate levels at baseline and arterial lactate levels at $24 \mathrm{~h}$ after the first dose. All of the patients' blood was collected for measurement of their thiamine pyrophosphate levels at baseline before intervention, and parameters of the SOFA scores, including creatinine, total bilirubin, the partial pressure of oxygen $\left(\mathrm{PaO}_{2}\right)$, the platelet count [14] and the vasopressor dependency index, were recorded. The Nutrition Risk in Critically ill (NUTRIC) score, which is a nutritional risk assessment tool developed and validated specifically for ICU patients, was recorded [15]. The Acute Physiology And Chronic Health Evaluation II (APACHE II) score was also recorded [16].

Initial sample sizing was calculated according to the primary endpoint: vasopressor-free day of norepinephrine administration among patients with septic shock from a previous study [17]. To detect a mean $20 \%$ reduction duration of the thiamine group, we calculated the sample size with a 2-sided type 1 error of 0.05 , with a power of 0.80 . From this, we estimated the requirement of 31 patients per group, and the planned period for study was 10 months after first enrolment. We also planned an interim analysis.
A comparison of non-normally continuous data was assessed by the Wilcoxon rank sum test and is reported herein as the median with interquartile range. A comparison of normally continuous data was assessed by Student's t test and is reported herein as the mean with standard deviations. Categorical variables are presented as percentages and were compared using the chi-square or Fisher exact test, as appropriate. A repeated measurement of the SOFA score and vasopressor dependency index within 7 days was analysed by a linear mixed model, and the worst value was imputed to the variable for patients who died during follow-up. For post hoc analysis, we also analysed the linear mixed model by adjusting the baseline and imputing the worst value to the variable for patients who died during follow-up. Kaplan-Meier curves were created for survival and compared with the log-rank test. Statistical analyses were performed using Stata version 15. All hypothesis tests were significant at a level of $p<0.05$. The analysis was performed with intention to treat.

\section{Results}

After a total of 10 months, our inclusion criteria were met by 62 patients. From this number, 12 patients were excluded (Fig. 1); the remaining 50 patients were randomized into 2 groups (patient characteristics are shown in Table 1). The predefined sample size was not reached since the number of cases in our hospital was not enough as planned. We found no statistically significant difference in vasopressor free-days between the thiamine group and

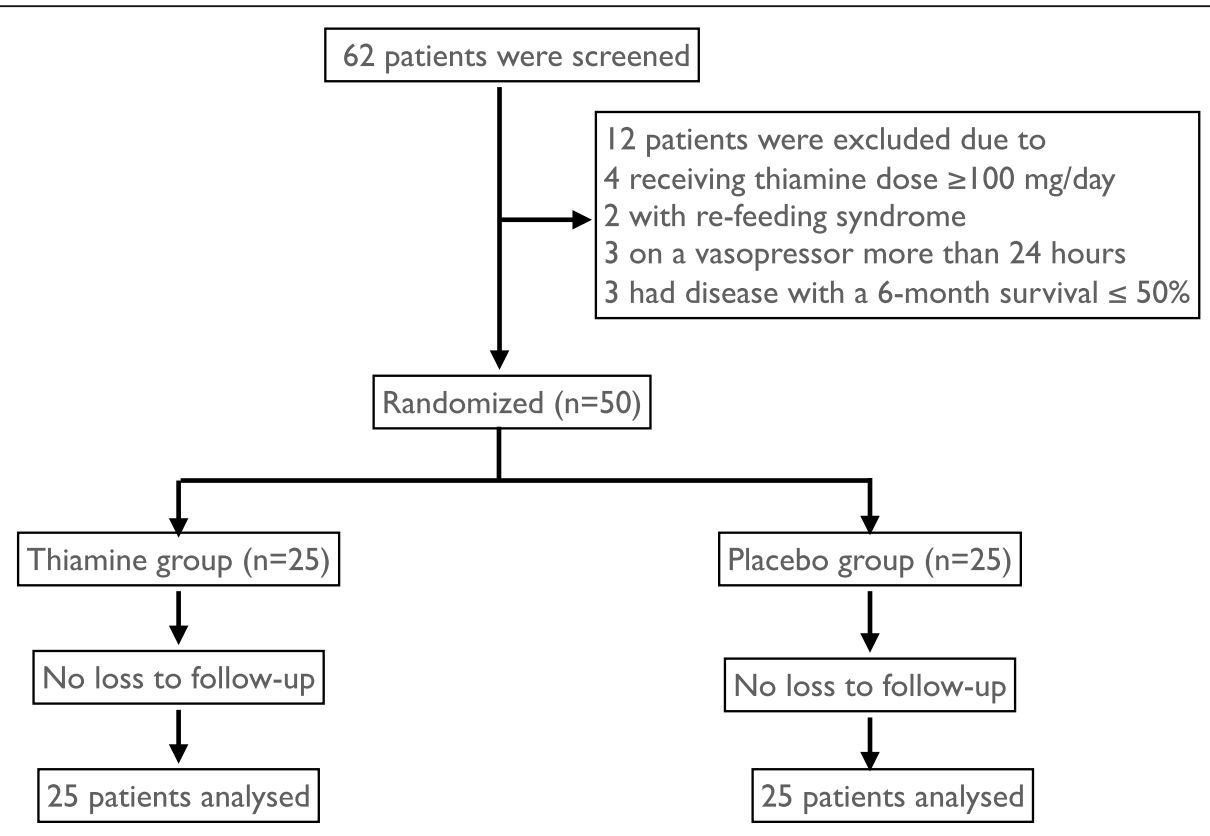

Fig. 1 Consort flow diagram 
Table 1 Baseline characteristics of the study patients

\begin{tabular}{|c|c|c|}
\hline Variables & $\begin{array}{l}\text { Thiamine } \\
(n=25)\end{array}$ & $\begin{array}{l}\text { Placebo } \\
(n=25)\end{array}$ \\
\hline \multicolumn{3}{|l|}{ Demographic } \\
\hline Age, yr, mean (SD) & $64(19.2)$ & $66(16.7)$ \\
\hline Sex, male, n (\%) & $17(68)$ & $12(48)$ \\
\hline Weight, mean (SD) & $62.5(20.5)$ & $61.0(14.6)$ \\
\hline $\mathrm{BMI}, \mathrm{kg} / \mathrm{m}^{2}$, mean (SD) & $23.3(6.5)$ & $23.6(5.7)$ \\
\hline Medical ICU, n (\%) & $16(64)$ & $22(88)$ \\
\hline Duration of vasopressor treatment, hr., median (IQR) & $11(7-17)$ & $10(5-12)$ \\
\hline \multicolumn{3}{|l|}{ Mechanical ventilation and severity of illness } \\
\hline Mechanical ventilation at the time of enrolment, $\mathrm{n}(\%)$ & $19(76)$ & $25(100)$ \\
\hline APACHE II score, mean (SD) & $26(7.6)$ & $29(6.1)$ \\
\hline SOFA score at enrolment, mean (SD) & $10(3.9)$ & $11(2.5)$ \\
\hline NUTRIC score, mean (SD) & $6(2.0)$ & $7(1.7)$ \\
\hline Norepinephrine equivalent dose ${ }^{a}$, mcg/kg/min, median (IQR) & $0.24(0.09-0.34)$ & $0.20(0.07-0.33)$ \\
\hline \multicolumn{3}{|l|}{ Comorbidities, n (\%) } \\
\hline Diabetes mellitus & $12(48)$ & $15(60)$ \\
\hline Hypertension & $14(56)$ & $20(80)$ \\
\hline Cerebrovascular disease & $7(28)$ & $7(28)$ \\
\hline Coronary artery disease & $2(8)$ & $4(16)$ \\
\hline Chronic heart failure & $3(12)$ & $4(16)$ \\
\hline Chronic obstructive pulmonary disease & $0(0)$ & $0(0)$ \\
\hline Liver disease & $5(20)$ & $4(16)$ \\
\hline ESRD on haemodialysis & $1(4)$ & $4(16)$ \\
\hline Chronic kidney disease & $7(28)$ & $6(24)$ \\
\hline Cancer & $9(36)$ & $11(44)$ \\
\hline \multicolumn{3}{|l|}{ Laboratory values at enrolment } \\
\hline White blood count, $\times 10^{3}$, median (IQR) & $11.9(5.7-18.9)$ & $7.8(1.5-15.2)$ \\
\hline Haemoglobin, g/dl, mean (SD) & $10.1(1.9)$ & $10.0(1.7)$ \\
\hline Blood urea nitrogen, mg/dl, median (IQR) & $36(22-58)$ & $43(20-58)$ \\
\hline Creatinine, mg/dl, median (IQR) & $1.9(1.2-2.8)$ & $1.7(1.3-2.1)$ \\
\hline Glucose, mg/dl, mean (SD) & $161(80)$ & $130(47)$ \\
\hline Lactate, mmol/l, median (IQR) & $2.9(2.3-3.5)$ & $2.8(2.1-5.6)$ \\
\hline Thiamine deficiency, n (\%) & $0(0)$ & $2(8)$ \\
\hline Thiamine level, median (IQR) & $103.9(77.8-127.0)$ & $86.0(56.6-124.9)$ \\
\hline C-reactive protein, median (IQR) & $213.4(143.6-261.1)$ & $177.1(81.5-249.9)$ \\
\hline \multicolumn{3}{|l|}{ Treatment } \\
\hline Crystalloid, ml, median (IQR) & $1500(800-2500)$ & $1400(1000-2500)$ \\
\hline Colloid, ml, median (IQR) & $250(250-500)$ & $250(0-500)$ \\
\hline Duration of sedation, hr., median (IQR) & $1.6(0-4.0)$ & $2.0(0-4.0)$ \\
\hline Duration of muscle relaxant, hr., median (IQR) & $0(0)$ & $0(0-1.0)$ \\
\hline Hydrocortisone, n (\%) & $15(60)$ & $16(64)$ \\
\hline
\end{tabular}


Table 1 Baseline characteristics of the study patients (Continued)

\begin{tabular}{|c|c|c|}
\hline Variables & $\begin{array}{l}\text { Thiamine } \\
(n=25)\end{array}$ & $\begin{array}{l}\text { Placebo } \\
(n=25)\end{array}$ \\
\hline Terlipressin, n (\%) & $2(8)$ & $1(4)$ \\
\hline Methylene blue, n (\%) & $1(4)$ & $2(8)$ \\
\hline Cytokine removal, n (\%) & $0(0)$ & $1(4)$ \\
\hline
\end{tabular}

$n$ number, $S D$ standard deviation, $h r$. hour, IQR interquartile range, BMI body mass index, APACHE II Acute Physiology and Chronic Health Evaluation, SOFA Sequential Organ Failure Assessment, NUTRIC Nutrition Risk in the Critically ill, ESRD end-stage renal disease

${ }^{a}$ The norepinephrine equivalent dose was calculated as [norepinephrine $(\mu \mathrm{g} / \mathrm{min})+[$ dopamine $(\mu \mathrm{g} / \mathrm{kg} / \mathrm{min}) \div 2]+[$ epinephrine $(\mu \mathrm{g} / \mathrm{min})]+[\mathrm{phenylephrine}(\mu \mathrm{gg} /$ $\min ) \div 10][18]$

placebo group (mean of 4.9 days $\pm 1.9 \mathrm{SD}$ in the thiamine group and mean of $4.0 \pm 2.7 \mathrm{SD}$ in the placebo group [ $p$ value: 0.197 , mean difference: $-0.9,95 \%$ CI: -2.9 to 0.5$]$ ).

However, there was a statistically significant difference in the vasopressor dependency index, as in a reduction within $24 \mathrm{~h}$ in the thiamine group. The median was 0.14 $\mathrm{mmHg}^{-1}$ (IQR: 0.03 to 0.26 ), which was greater than that in the placebo group, with a median of $0.03 \mathrm{~mm} \mathrm{Hg}^{-1}$ (IQR: -0.09 to 0.12 ), $p$ value: 0.020 . Moreover, the lactate reduction within $24 \mathrm{~h}$ in the thiamine group had a median of $1.0 \mathrm{mmol} / \mathrm{L}$ (IQR: -0.3 to 1.8 ) and was greatly reduced, more so than in the placebo group: median: $0.5 \mathrm{mmol} / \mathrm{L}$ (IQR: -0.2 to 1.0 ), $p$ value: 0.024 (Table 2).

Changes in SOFA scores and the vasopressor dependency index over 7 days are shown in the Supplement. There was no statistically significant difference between the groups.

The 28-day mortality in our study is shown using the Kaplan-Meier failure estimates (Fig. 2), and there was no statistically significant difference ( $p$ value: 0.395 ). In the thiamine group, 5 patients died $(20 \%)$, while in the placebo group, 7 patients died (28\%) ( $p$ value: 0.741 ) within 28 days. No patients in the thiamine group died within 7 days while receiving thiamine administration; however, 4 patients in the placebo group died over the course of 7 days (Table 2). No adverse effects from thiamine, such as rash, itchy, red skin or anaphylaxis, occurred during the study.
For post hoc analysis of the vasopressor dependency index and SOFA scores within 4 days, it was found that changes in SOFA scores within 4 days were significantly different between the groups ( $\mathrm{p}$ value: 0.04) (Fig. 3); however, changes in the vasopressor dependency index were not significant ( $\mathrm{p}$ value: 0.523 ) (Fig. 4).

\section{Discussion}

Taking into account the major limitations of early stopping the study and small sample size, no evidence of differences in vasopressor-free days between the patients receiving thiamine or a placebo in 7 days was found. We found that $24 \mathrm{~h}$ after administration of the intervention, patients in the thiamine group had a reduction in their vasopressor dependency index as well as decreased lactate, more so than those in the placebo group. No other secondary outcomes were significantly different.

In general, the rationale for thiamine administration in septic shock is supported by a high incidence of low thiamine levels in critically ill patients and a high thiamine consumption state from increased mitochondrial oxidative stress during critical illnesses [19]. Thiamine plays an important role in producing $\mathrm{NADH}$ during glutathione cycling, inhibiting ROS in mitochondria, and therefore may improve microvascular function [4]. From a preliminary study of the thiamine, ascorbic acid, and hydrocortisone drug combination [20] and the post hoc analysis of thiamine supplementation [21], thiamine may prevent

Table 2 Primary outcome and secondary outcomes

\begin{tabular}{|c|c|c|c|}
\hline Variables & $\begin{array}{l}\text { Thiamine } \\
(N=25)\end{array}$ & $\begin{array}{l}\text { Placebo } \\
(N=25)\end{array}$ & $p$-value \\
\hline \multicolumn{4}{|l|}{ Primary outcome } \\
\hline No. of vasopressor-free day, mean (SD) & $4.9(1.9)$ & $4(2.7)$ & 0.197 \\
\hline \multicolumn{4}{|l|}{ Secondary outcomes } \\
\hline 24-h lactate reduction, mmol/L, median (IQR) & $1.0(-0.3$ to 1.8$)$ & $0.5(-0.2$ to 1.0$)$ & $0.024^{*}$ \\
\hline 24-h vasopressor dependency index reduction, $\mathrm{mmHg}^{-1}$, median (IQR) & $0.14(0.03$ to 0.26$)$ & $0.03(-0.09$ to 0.12$)$ & $0.020^{*}$ \\
\hline 28-day mortality, no./total no. (\%) & $5(20)$ & $7(28)$ & 0.741 \\
\hline SOFA scores day 4 - day 1 , median (IQR) & $-4(-5.25$ to -1.00$)$ & $-4.00(-6.25$ to -1.50$)$ & 0.409 \\
\hline
\end{tabular}

No. number, $S D$ standard deviation, $I Q R$ interquartile range

${ }^{*} p$-value < 0.05 


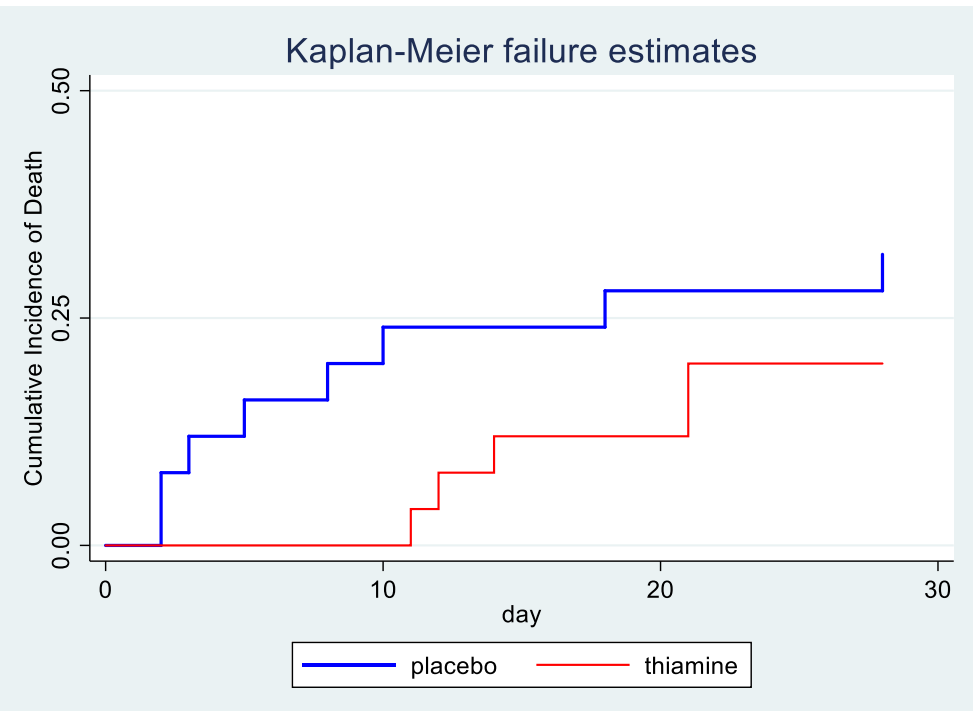

Fig. 2 Kaplan-Meier failure estimation 28-day mortality

organ failure, especially regarding the renal function of patients with septic shock, and may improve global oxygen consumption after CABG surgery [22].

The results of the present study suggest that no difference in the number of vasopressor-free days, mortality, SOFA score or vasopressor dependency index occurred within 7 days. However, within the statistical power limitations, these results also suggest that early administration of thiamine (within $24 \mathrm{~h}$ ), reduced lactate and the vasopressor dependency index, also within $24 \mathrm{~h}$. Although only a few of the individuals in this study population were thiamine deficient, this number was still less than those other studies. This situation may have been due to the fact that this study differed in population, race, nutritional status and/or early randomization [6, 9]. Larger trials are needed to evaluate the effects of thiamine alone on vasopressor requirements in patients with septic shock.

In our study, we found that thiamine administration could reduce lactate levels compared with those in patients not receiving thiamine. The outcomes were different from previous findings by Donnino et al. [9],

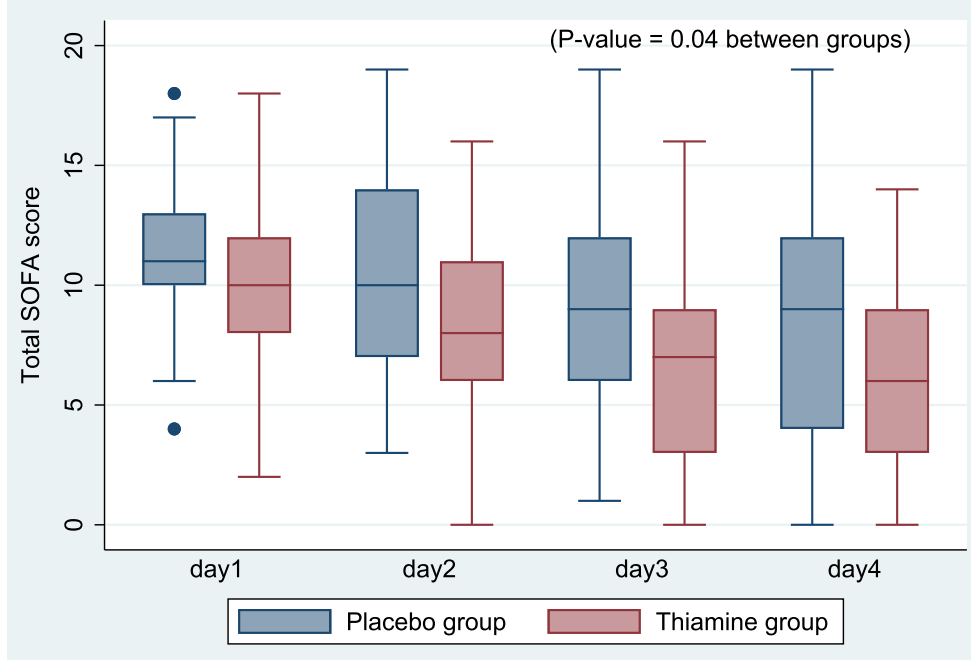

Fig. 3 Post hoc exploratory analysis of changes in SOFA scores within 4 days 


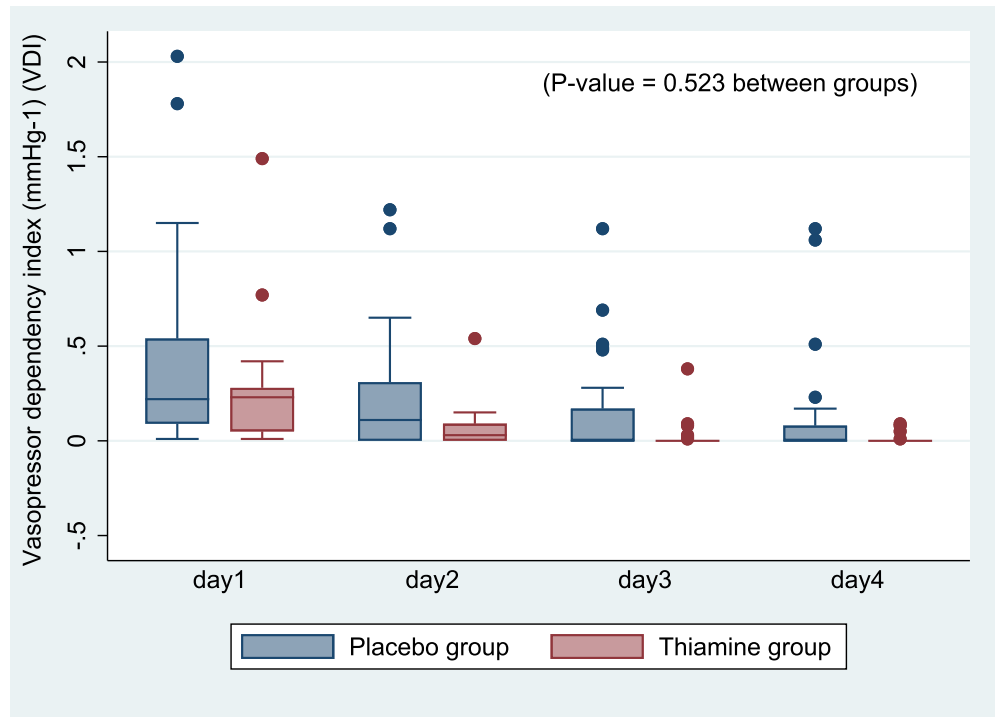

Fig. 4 Post hoc exploratory analysis of changes in the vasopressor dependency index within 4 days

in which compared to placebo, thiamine supplementation did not decrease 24-h lactate levels in patients with septic shock and elevated lactate $>3 \mathrm{mmol} / \mathrm{L}$. However, it improved the 24-h lactate clearance in patients with a laboratory-confirmed thiamine deficiency via liquid chromatography/tandem mass spectrometry by Quest Diagnostics, which was different from the findings in our study. Apart from the methods, contrasting outcomes might have occurred in our study due to the limited time dependence of vasopressors $(1-24 \mathrm{~h})$ and the earlier enrolment and drug administration than those of other studies [7, 9]. Additionally, our study was different from other investigations, as we used the definition of septic shock taken from the sepsis 3 definition [23]. We included participants with a lactate level $>2 \mathrm{mmol} / \mathrm{L}$.

Regarding physical effects, this study showed a greater reduction in the 24-h vasopressor dependency index in the thiamine group than in the placebo group. We assumed that this improved the microvascular function, as in the pentose-phosphate shuttle that occurs in mitochondria. However, we did not test clinical changes in the cardiac index or vascular resistance. Moreover, we cannot exactly explain the mechanism.

In the post hoc analysis of our study, the outcome of organ failure improved in the first 4 days; therefore, the administration of thiamine might not necessarily last long. On the other hand, the use of thiamine for less than 4 days in the study of Hwang et al. (who administered thiamine and vitamin $\mathrm{C}$ to septic shock patients for 2 days) did not improve the SOFA score [24]. However, the administration of thiamine in combination with corticosteroids and ascorbic acid for 4 days in a recent randomized trial likewise did not reduce the SOFA score during the first $72 \mathrm{~h}$ [25].

Strengths of our study. First, the design of this study used double blind randomization in that we blinded both the patients and investigators to reduce selection bias. Second, we included patients early and limited the time to randomization. Third, this trial measured thiamine levels at the time of randomization before administering the intervention, which showed a background of thiamine levels in our population with septic shock.

Our study did have limitations. First, it had a small sample size and an early stopping point and was insufficiently powered; this limited validity of the results may have led to selection bias. Moreover, the risk of type I and II errors should be taken into consideration and the results of post hoc analyses should be interpreted with caution. Further studies are needed to evaluate the effectiveness of thiamine on vasopressor requirements. Second, we did not compare differing dosage levels of thiamine. The dosage of thiamine in our study was 200 mg IV every $12 \mathrm{~h}$ for 7 days, which was different from that in a study by Woolum JA. et al. [7], in that nearly two-thirds of their thiamine group received high doses of thiamine (500 mg IV) every $8 \mathrm{~h}$ for 3 days. In their study, it was found that such levels could decrease mortality. Higher thiamine doses may offer the advantage of improved, passive absorption into the CNS along with improvements in thiamine exposure due to the rapid elimination of thiamine from the serum into urine [26]. Additionally, we did not perform analyses or control the effects of volume resuscitation and other drugs in the septic shock cocktails, consisting of thiamine, 
hydrocortisone and vitamin C. In our study, more than $60 \%$ of the patients from both groups received hydrocortisone, which has potent effects on resolution of shock, and the patient characteristics were severe, similar to the study by Fujii and colleagues in that hydrocortisone might mask the effects of thiamine [27].

\section{Conclusions}

Thiamine was not associated to a significant reduction in vasopressor-free days over 7-days in comparison to placebo in patients with septic shock. Administration of thiamine could be associated with a reduction in vasopressor dependency index and lactate level within $24 \mathrm{~h}$. The study is limited mainly by early stopping and low sample size. Further studies are needed to evaluate the effectiveness of thiamine on vasopressor requirements.

\section{Supplementary Information}

Supplementary information accompanies this paper at https://doi.org/10. 1186/s12871-020-01195-4.

Additional file 1: Figure 1. Changes of SOFA scores within 7 days. Figure 2. Changes of the Vasopressor Dependency index within 7 days

\section{Abbreviations}

ROS: reactive oxygen species; NADPH: nicotinamide adenine dinucleotide phosphate; $\mathrm{NADH}$ : nicotinamide adenine dinucleotide; CABG: coronary artery bypass graft; SOFA: Sequential Organ Failure Assessment; PaO2: partial pressure of oxygen; NUTRIC: Nutrition Risk in the Critically ill; ESRD: End-stage renal disease

\section{Acknowledgements}

We would like to thank all of staff at the medical intensive care unit at Ramathibodi hospital for their help throughout the study and Andrew Tait, from the International Affairs Department, for proofing English writing. I wish to thank my colleagues and family for their support and encouragement throughout the research period.

\section{Authors' contributions \\ SP was engaged in the study design, data collection, data analysis and data interpretation and drafting of the work. SM was engaged in the study design, data interpretation, and contributed to the revision of the manuscript. VT was engaged in the design of the work and draft revisions. PK, PS and PS were engaged design of the work. All authors have read and approved the final manuscript.}

\section{Funding}

Suttasinee Petsakul is a research fellow, and currently supported by research funds form the Faculty of Medicine, Ramathibodi hospital. This funding had not been involved in the study design, data collection, analysis, data interpretation or manuscript preparation.

\section{Availability of data and materials}

The datasets used and/or analysed during this current study are available from the corresponding author, upon reasonable request.

\section{Ethics approval and consent to participate}

The study was approved by The Committee on Human Rights, Related to Research Involving Human Subjects, based on the Declaration of Helsinki, Faculty of Medicine Ramathibodi Hospital, Mahidol University (protocol number: ID 12-60-05). Informed consent was required before enrolment, and was given and signed by either the patient or their legal representative.
Consent for publication

Not applicable.

\section{Competing interests}

The authors declare that they have no competing interests.

\section{Author details}

${ }^{1}$ Department of Critical Care Medicine, Faculty of Medicine, Ramathibodi Hospital, Mahidol University, Ratchathewi, Bangkok 10400, Thailand. ${ }^{2}$ Department of Anesthesiology, Faculty of Medicine, Prince of Songkla University, Hatyai, Songkhla 90110, Thailand. ${ }^{3}$ Department of Anesthesiology, Faculty of Medicine, Ramathibodi Hospital, Mahidol University, Bangkok, Thailand. ${ }^{4}$ Piyavate Hospital, Bangkok, Thailand. ${ }^{5}$ Department of Internal Medicine, Faculty of Medicine, Ramathibodi Hospital, Mahidol University, Bangkok, Thailand. ${ }^{6}$ Department of Surgery, Faculty of Medicine,

Ramathibodi Hospital, Mahidol University, Bangkok, Thailand. ${ }^{7}$ Department of Emergency Medicine, Ramathibodi Hospital, Mahidol University, Bangkok, Thailand.

Received: 2 June 2020 Accepted: 20 October 2020

Published online: 09 November 2020

\section{References}

1. Butterworth RF: Thiamine. Modern Nutrition in Health and Disease. Edited by: Shils ME. 2006, Lippincott: Williams \& Wilkins, 426-433. 10.

2. de Andrade JAA, Gayer CRM, Nogueira NPA, Paes MC, Bastos V, Neto J, et al. The effect of thiamine deficiency on inflammation, oxidative stress and cellular migration in an experimental model of sepsis. J Inflamm (Lond). 2014;11:11.

3. Gioda CR, de Oliveira BT, Primola-Gomes TN, de Lima DC, Campos PP, Capettini Ldos S, et al. Cardiac oxidative stress is involved in heart failure induced by thiamine deprivation in rats. Am J Physiol Heart Circ Physiol. 2010;298(6):H2039-45

4. Moskowitz A, Andersen LW, Huang DT, Berg KM, Grossestreuer AV, Marik PE, et al. Ascorbic acid, corticosteroids, and thiamine in sepsis: a review of the biologic rationale and the present state of clinical evaluation. Crit Care. 2018;22(1):283.

5. Shimon I, Almog S, Vered Z, Seligmann H, Shefi M, Peleg E, et al. Improved left ventricular function after thiamine supplementation in patients with congestive heart failure receiving long-term furosemide therapy. Am J Med. 1995;98(5):485-90.

6. Cruickshank AM, Telfer AB, Shenkin A. Thiamine deficiency in the critically ill. Intensive Care Med. 1988;14(4):384-7.

7. Woolum JA, Abner EL, Kelly A, Thompson Bastin ML, Morris PE, Flannery AH. Effect of thiamine administration on lactate clearance and mortality in patients with septic shock. Crit Care Med. 2018;46(11):1747-52.

8. Miyamoto $Y$, Aso S, Iwagami M, Yasunaga $H$, Matsui $H$, Fushimi $K$, et al. Association between IV thiamine and mortality in patients with septic shock: a Nationwide observational study. Crit Care Med. 2020;48(8):1135-9.

9. Donnino MW, Andersen LW, Chase M, Berg KM, Tidswell M, Giberson T, et al. Randomized, double-blind, placebo-controlled trial of thiamine as a metabolic resuscitator in septic shock: a pilot study. Crit Care Med. 2016; 44(2):360-7.

10. Lomivorotov W, Moroz G, Ismoilov S, Shmyrev V, Efremov S, Abubakirov M, et al. Sustained high-dose thiamine supplementation in high-risk cardiac patients undergoing cardiopulmonary bypass: a pilot feasibility study (the APPLY trial). J Cardiothorac Vasc Anesth. 2020;34(3):594-600.

11. Rhodes A, Evans LE, Alhazzani W, Levy MM, Antonelli M, Ferrer R, et al. Surviving Sepsis campaign: international guidelines for Management of Sepsis and Septic Shock: 2016. Intensive Care Med. 2017;43(3):304-77.

12. Lu J, Frank EL. Rapid HPLC measurement of thiamine and its phosphate esters in whole blood. Clin Chem. 2008;54(5):901-6.

13. Cruz DN, Antonelli M, Fumagalli R, Foltran F, Brienza N, Donati A, et al. Early use of polymyxin B hemoperfusion in abdominal septic shock: the EUPHAS randomized controlled trial. JAMA. 2009;301(23):2445-52.

14. Vincent JL, Moreno R, Takala J, Willatts S, De Mendonca A, Bruining H, et al. The SOFA (Sepsis-related organ failure assessment) score to describe organ dysfunction/failure. On behalf of the working group on Sepsis-related problems of the European Society of Intensive Care Medicine. Intensive Care Med. 1996;22(7):707-10. 
15. Heyland DK, Dhaliwal R, Jiang X, Day AG. Identifying critically ill patients who benefit the most from nutrition therapy: the development and initial validation of a novel risk assessment tool. Crit Care. 2011;15(6):R268.

16. Knaus WA, Draper EA, Wagner DP, Zimmerman JE. APACHE II: a severity of disease classification system. Crit Care Med. 1985;13(10):818-29.

17. Zabet MH, Mohammadi M, Ramezani M, Khalili H. Effect of high-dose ascorbic acid on vasopressor's requirement in septic shock. J Res Pharm Pract. 2016;5(2):94-100.

18. Russell JA, Walley KR, Singer J, Gordon AC, Hebert PC, Cooper DJ, et al. Vasopressin versus norepinephrine infusion in patients with septic shock. N Engl J Med. 2008;358(9):877-87.

19. Carre JE, Singer M. Cellular energetic metabolism in sepsis: the need for a systems approach. Biochim Biophys Acta. 2008;1777(7-8):763-71.

20. Marik PE, Khangoora V, Rivera R, Hooper MH, Catravas J. Hydrocortisone, vitamin $\mathrm{C}$, and thiamine for the treatment of severe Sepsis and septic shock: a retrospective before-after study. Chest. 2017;151(6):1229-38.

21. Moskowitz A, Andersen LW, Cocchi MN, Karlsson M, Patel PV, Donnino MW. Thiamine as a renal protective agent in septic shock. A secondary analysis of a randomized, double-blind, placebo-controlled trial. Ann Am Thorac Soc. 2017;14(5):737-41.

22. Andersen LW, Holmberg MJ, Berg KM, Chase M, Cocchi MN, Sulmonte C, et al. Thiamine as an adjunctive therapy in cardiac surgery: a randomized, double-blind, placebo-controlled, phase II trial. Crit Care. 2016;20:92.

23. Singer M, Deutschman CS, Seymour CW, Shankar-Hari M, Annane D, Bauer $M$, et al. The third international consensus definitions for Sepsis and septic shock (Sepsis-3). JAMA. 2016:315(8):801-10.

24. Hwang SY, Ryoo SM, Park JE, Jo YH, Jang DH, Suh GJ, et al. Combination therapy of vitamin $\mathrm{C}$ and thiamine for septic shock: a multi-Centre, doubleblinded randomized, controlled study. Intensive Care Med. 2020. Available from: https://link.springer.com/article/10.1007/s00134-020-06191-3. [cited 2020 Oct 26].

25. Moskowitz A, Huang DT, Hou PC, Gong J, Doshi PB, Grossestreuer AV, et al. Effect of ascorbic acid, corticosteroids, and thiamine on organ injury in septic shock: the ACTS randomized clinical trial. JAMA. 2020;324(7):642-50.

26. Wrenn KD, Murphy F, Slovis CM. A toxicity study of parenteral thiamine hydrochloride. Ann Emerg Med. 1989;18(8):867-70.

27. Fujii T, Luethi N, Young PJ, Frei DR, Eastwood GM, French CJ, et al. Effect of vitamin C, hydrocortisone, and thiamine vs hydrocortisone alone on time alive and free of vasopressor support among patients with septic shock: the VITAMINS randomized clinical trial. JAMA. 2020;323(5):423-31.

\section{Publisher's Note}

Springer Nature remains neutral with regard to jurisdictional claims in published maps and institutional affiliations.

Ready to submit your research? Choose BMC and benefit from:

- fast, convenient online submission

- thorough peer review by experienced researchers in your field

- rapid publication on acceptance

- support for research data, including large and complex data types

- gold Open Access which fosters wider collaboration and increased citations

- maximum visibility for your research: over $100 \mathrm{M}$ website views per year

At $\mathrm{BMC}$, research is always in progress.

Learn more biomedcentral.com/submissions 